\title{
Contrast sensitivity gratings in glaucoma family screening
}

\author{
R. A. Hitchings, D. J. POWELl, G. B. ARDEN, And R. M. CARTER \\ From Moorfields Eye Hospital, High Holborn, London WC1V $7 A N$
}

SUMMARY Contrast sensitivity was measured in the eyes of 200 consecutive patients attending the glaucoma family screening unit. One-third of the patients screened had an abnormal contrast sensitivity. Positive correlation $(p<0.01)$ existed between this abnormal contrast sensitivity and cup : disc ratio, visual field loss, and age. No such correlation existed between contrast sensitivity and intraocular pressure.

Since the introduction by $\operatorname{Arden}^{1}$ of a booklet containing contrast gratings of various spatial frequencies contrast sensitivity has been used to assess visual function in a number of ocular diseases. Visual function has been assessed by this method in normal eyes, ${ }^{1-3}$ in chronic glaucoma, ${ }^{2-6}$ optic neuritis, ${ }^{78}$ and diabetes. ${ }^{9}$ In a preliminary study Arden and Hitchings ${ }^{10}$ found abnormal contrast sensitivities in a group of family members of glaucoma patients and speculated whether this test could be of use in screening for the future development of glaucoma.

Glaucoma family screening may detect primary open-angle glaucoma in up to $10 \%$ of siblings, ${ }^{11}$ while on long-term follow-up of siblings this figure rises to $16 \%^{12}$ Despite these figures large numbers of patients considered at risk because of a positive family history of glaucoma will never show signs of developing this disease. Any method of assessment which might point to the future development of glaucoma in this group and thus reduce the numbers that require to be followed up by screening clinics is worth investigating. Because of the results obtained in a preliminary study, ${ }^{10}$ suggesting that a proportion of 'normal' patients attending a glaucoma family clinic produce abnormally high scores with contrast sensitivity gratings, it seemed worthwhile to screen a larger number of patients by this method.

\section{Material and methods}

Two hundred consecutive patients attending the Glaucoma Family Clinic at Moorfields Eye Hos-

Correspondence to Mr R. A. Hitchings, FRCS. pital were entered into the study. Clinical examination of the eyes was carried out by one author (R.A.H.). The following tests were carried out.

(i) Visual acuity; best corrected acuity on a Snellen's chart assessed independently for each eye. A note was made if the visual acuity was $\leqslant 6 / 9$.

(ii) Visual field. Friedmann field analysis with the appropriate spectacle correction was carried out for each eye. Suprathreshold analysis was carried out. An abnormal result was considered to have occurred if 3 or more spots of greater than $0.4 \log$ units decrease in sensitivity were noted. Spots missed at the time of the initial run were re-presented, and only those spots missed on 2 occasions were counted.

(iii) Anterior chamber depth measurement by Haag-Streit pachometry. A note was made of those eyes with an anterior chamber depth of $<2.5 \mathrm{~mm}$ axially.

(iv) Gonioscopy. Special emphasis was placed on the presence or absence of dependent pigment on the trabecular meshwork of the anterior chamber angle.

(v) The vertical cup : disc ratio was measured by monocular direct ophthalmoscopy. A note was made if the cup : disc ratio was greater than 0.5 in either eye.

(vi) The patient's age.

An independent examination of the patient's contrast sensitivity was carried out. Thus the results of clinical examination of the eye and contrast sensitivity were kept separate until the conclusion of the study. Contrast sensitivity was measured for each eye by the method described by Arden. ${ }^{1}$ 
Table 1 Frequency of recorded physical signs

\begin{tabular}{lcc}
\hline Physical signs & Number & Percentage \\
\hline Grating score $\geqslant 82$ & 149 & $38 \cdot 5$ \\
Visual acuity $<6.9$ & 16 & $4 \cdot 1$ \\
Abnormal pressure $(>21)$ & 55 & $14 \cdot 2$ \\
C/D ratio > 0.5 & 114 & $29 \cdot 4$ \\
Anterior chamber depth $<2.5$ & 81 & $20 \cdot 9$ \\
Abnormal visual field & 94 & $24 \cdot 3$ \\
Presence of dependent angle pigment & 157 & $40 \cdot 1$ \\
\hline
\end{tabular}

\section{Results}

Two hundred patients entered the study; 387 eyes were included. The remaining 13 eyes were excluded because of concomitant disease, such as amblyopia, corneal nebulae, retinal degeneration, and cataract considered sufficient to reduce the acuity to below $6 / 9$.

The frequency of each of the recorded physical signs is noted in Table 1. A correlation matrix between these physical signs was determined. Those correlations that were significant $(p<0.01)$ are displayed diagrammatically in Fig. 1. The correlations between the abnormal signs in Fig. 1 remain significant when age is partialled out. There was no significant correlation between the grating score and intraocular pressure.

Four eyes were discovered to have primary open-angle glaucoma, and these eyes all had abnormal grating scores.

\section{Discussion}

Arden ${ }^{1}$ was able to set an arbitrary upper limit of 82 for normal eyes when tested with his booklet. One-third of the patients tested in this series had scores greater than this, despite the presence in most eyes of a normal visual acuity and intraocular pressure.
As noted above, the physical signs cup : disc ratio, anterior chamber depth, visual field defects, and angle pigment were also detected in $20-40 \%$ of the subjects. While no control group was studied in this series, the study plan whereby there was an independent assessment of gratings sensitivity and physical signs meant that correlations between grating score and the other signs may be regarded as uncontaminated by experimental bias. Clearly this cannot be known to be the case for the raw data.

Although only 4 patients were discovered to have chronic simple glaucoma, each had an abnormally high grating score. This confirms earlier reports. ${ }^{12}$ 4-6

The correlation of grating score with age has also been reported in other series. ${ }^{13} 14$ However, the group of patients studied in this series may not be regarded as 'normal'. The correlation of age with grating score might be the result of an age-related degeneration occurring in an eye that will subsequently show signs of glaucoma.

The patients studied did not show positive correlation between grating score and intraocular pressure. Although intraocular pressures greater than $35 \mathrm{mmHg}$ are rapidly followed by visual loss and glaucomatous cupping, ${ }^{15}$ this is not necessarily the case for patients with intraocular pressures in the mid 20s. In fact many patients with intraocular pressures in the middle 20 s may never proceed to develop glaucoma. ${ }^{16} 17$ The ocular hypertensive patients examined had intraocular pressures in the mid 20s; not only may they have not had time to develop visual damage from this raised tension but they may fall within the group of ocular hypertensives who never seem to do so.

The value of assessing contrast sensitivity in a glaucoma screening may lie, firstly, in the positive correlation with both a large cup : disc ratio and, independently, with visual field loss as defined above;

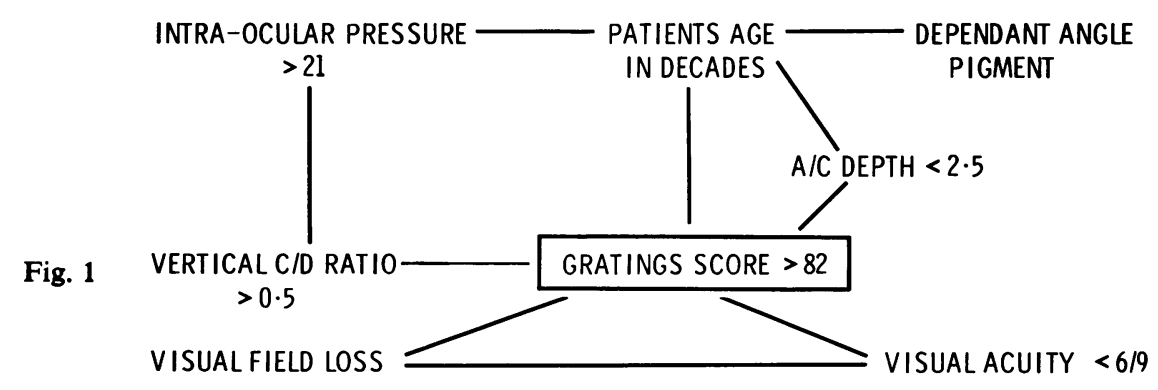

SIGNIFICANT ( $P<0.01)$ CORRELATIONS BETWEEN PHYSICAL SIGNS. 
Secondly, in longitudinal studies of glaucoma suspects, for progressive worsening of contrast sensitivity may possibly be a precursor of overt glaucomatous damage.

\section{References}

1 Arden GB. The importance of measuring contrast sensitivity in cases of visual disturbance. $\mathrm{Br} \mathrm{J} \mathrm{Ophthalmol}$ 1978; 62: 198-209.

2 Hus-Wenges C, Stamper RL, Sopher M. Arden contrast sensitivity testing in normal, glaucoma suspects and chronic glaucoma patients. Invest Ophthalmol Visual Sci 1980; suppl: Association for Research in Vision and Ophthalmology.

3 Levy NS, Ozaki K, Bonney RB. Responses to the Arden modulation transfer function plates in normal eyes with optically altered visual acuity. Invest Ophthalmol Visual Sci 1980; suppl: Association for Research in Vision and Ophthalmology.

4 Arden GB, Jacobsen JJ. A simple grating test for contrast sensitivity; preliminary results indicate value in screening for glaucoma. Invest Ophthalmol Visual Sci 1978; 17: 23-32.

5 Fitzgerald CR, Enoch JM, Temme LA. Different functional changes recorded in open angle glaucoma and anterior ischaemic optic neuropathy. Invest Ophthalmol Visual Sci 1980; suppl: Association for Research in Vision and Ophthalmology.

6 Atkin A, Bodes-Wollner I, Wolkstein M, Moss A,
Podos SN. Abnormalities of central contrast sensitivity in glaucoma. Am J Ophthalmol 1979; 88: 205-11.

7 Arden GB, Gucukoglu AG. Grating test of contrast sensitivity in patients with retrobulbar neuritis. Am J Ophthalmol 1978; 96: 126-69.

8 Skalka HA. A comparison of Snellen's acuity, Ver acuity and Arden grating scores in monocular optic nerve disease. Br J Ophthalmol 1979; 64: 24-9.

9 Arden GB. Visual loss in patients with normal visual acuity. Trans Ophthalmol Soc UK 1978; 98: 219-31.

10 Arden GB, Hitchings RA. Grating visual assessment in the identification of glaucoma suspects in family screening clinic. Invest Ophthalmol Visual Sci 1980; suppl: Association for Research in Vision and Ophthalmology.

11 Hitchings RA. Glaucoma family screening. Res Clin Forums 1980; 2: 21-4.

12 Coakes RL. Role of the glaucoma family clinic. Res Clin Forums 1980; 2: 15-20.

13 Derefeld TG, Lennerstrand G, Lundh B. Age variations in normal human contrast sensitivity. Acta Ophthalmol (Kbh) 1979; 57: 679-90.

14 Skalka HW. Affect of age on Arden grating acuity. Br J Ophthalmol 1979; 64: 21-3.

15 Schappert-Kimmijser S. A five year follow-up of subjects with intra-ocular pressures of 22-30 without anomalies of visual field or optic nerve typical for glaucoma at first investigation. Ophthalmologica 1971 ; 162: 289-95.

16 Perkins ES. The Bedford glaucoma survey. I. Long-term follow-up or borderline cases. Br J Ophthalmol 1973; 57: 179-84.

17 Linner E. Ocular hypertension. I. The clinical course during ten years without therapy. Aqueous humour dynamics. Ophthalmologica 1976; 54: 707-20. 